\title{
Celebrating the 75th birthday of Professor Wladek Minor, one of the most accomplished Polish-American structural biologists
}

\author{
Mariusz Jaskolski1 ${ }^{12}$, Alexander Wlodawer ${ }^{3}$, Zbigniew Dauter ${ }^{3}$, Ivan G. Shabalin ${ }^{4}$ and \\ Maksymilian Chruszcz $^{5}$
}

1Department of Crystallography, Faculty of Chemistry, A. Mickiewicz University, Poznań, Poland; ${ }^{2}$ Center for Biocrystallographic Research, Institute of Bioorganic Chemistry, Polish Academy of Sciences, Poznań, Poland; ${ }^{3}$ Center for Structural Biology, National Cancer Institute, Frederick, MD, U.S.A.; ${ }^{4}$ Department of Molecular Physiology and Biological Physics, University of Virginia, Charlottesville, VA, U.S.A.; ${ }^{5}$ Department of Chemistry and Biochemistry, University of South Carolina, Columbia, SC, U.S.A.

This paper describes the scientific career and accomplishments of Professor Wladek Minor, who holds an endowed chair at the University of Virginia in Charlottesville, USA. Prof. Minor is a coauthor of data processing software used by macromolecular crystallographers world-wide, as well as of structural biology servers and of a repository for raw diffraction data. He made major contributions to the validation of biostructural data, with special focus on drug design targets and reproducibility in biomedical research. He is among the most highly cited molecular biologists ever.

Keywords: protein crystallography, structural biology, data mining, methods development, reproducibility, rational drug design

Received: 05 November, 2020; accepted: 09 November, 2020; available on-line: 21 January, 2021

๑e-mail: mariuszj@amu.edu.pl

Abbreviations: CCP4, Collaborative Computational Project No. 4; CSGID, Center for Structural Genomics of Infectious Diseases; MSCG, Midwest Center for Structural Genomics; NYSGRC, New York SGX Research Center for Structural Genomics; PDB, Protein Data Bank

Professor Wladek Minor (Fig. 1) will celebrate his 75th birthday in May 2021. He holds an appointment as the Harrison Distinguished Professor of Molecular Physiology and Biological Physics at the University of Virginia, Charlottesville, United States of America.

Wladek was educated in Poland, obtaining his M.Sc. degree in 1969 and his Ph.D. in 1977, both from the Physics Department at the University of Warsaw. His background during that period was in solid state physics and he initially worked in the group of Professor Bronisław Buras, a renowned physicist and the author of a high school textbook used throughout Poland. For a number of years, Wladek collaborated very closely with Tomasz Giebultowicz, who then worked in Warsaw and later became professor of physics at Oregon State University, Corvallis, USA. In addition to his very successful scientific work as a physicist at that time, Wladek was also involved in extensive teaching of undergraduate and graduate students in Warsaw.

Wladek's career took a major turn when he moved to the United States in 1985, arriving in West Lafayette, Indiana, to take up a postdoctoral position at the Physics Department. Once he and his wife, Dr. Iwona Minor, settled there, she joined the group of Professor Michael Rossmann, one of the icons of macromo-

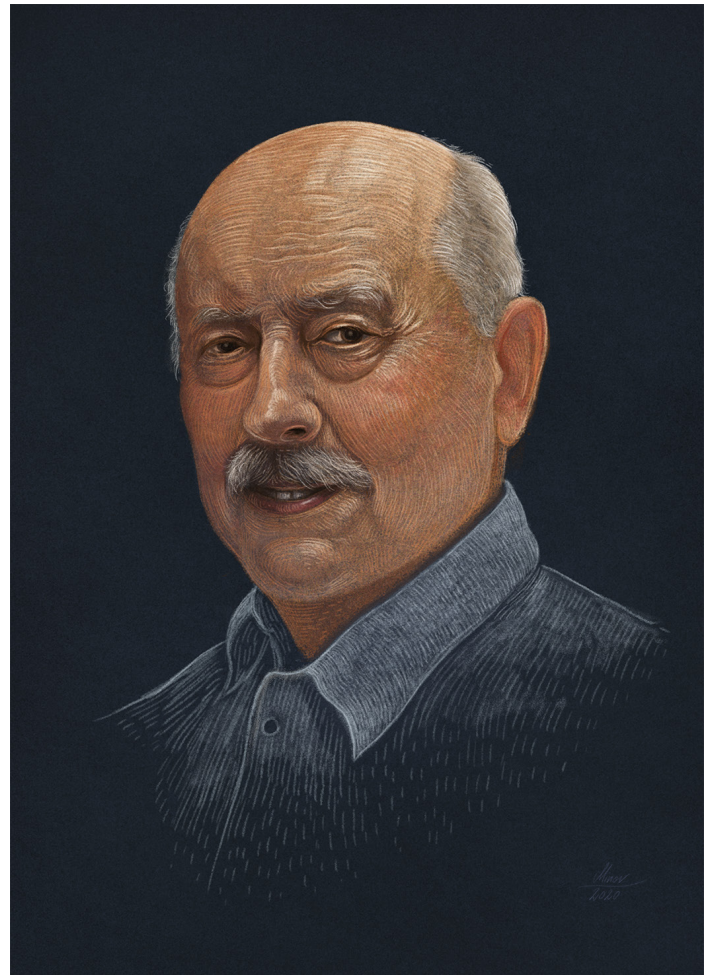

Figure 1. Portrait of Professor Wladek Minor drawn by Marcin Minor, 2020.

lecular crystallography. Professor Rossmann was a true leader in the field of crystallography of proteins and viruses, with an amazing portfolio of breakthrough accomplishments, including participation in the determination of the first protein structures and development of the method of molecular replacement, which still remains one of the main tools for macromolecular structure solution. Wladek quickly became aware of the advantages of switching his research to the most exciting area and he joined Professor Rossmann's group as well. The ten years spent at Purdue University, first as a postdoctoral research associate, and later as a research scientist, were exceedingly formative for Wladek's future career. He had to establish himself in a completely new field and quickly became very adept in solving crystal structures of macromolecules, such as enzymes and even viruses.

While at Purdue, Wladek started a very successful collaboration with his younger acquaintance from Warsaw, Zbyszek Otwinowski, currently professor of biochem- 
istry at the University of Texas Southwestern Medical Center, Dallas, USA. While still at Purdue, Wladek and Zbyszek commenced work on a tandem of computer programs, Denzo and Scalepack, as well as their graphics interface XDisplayF, which for a long time became the tools of choice for processing X-ray diffraction data obtained from macromolecular crystals.

Wladek's next major move took place in 1995, when he secured a faculty position at the University of Virginia and when, together with Zbyszek Otwinowski, he co-founded a company, HKL Research, Inc. (https:// www.hkl-xray.com/), with Iwona Minor as the company CEO. This established a very successful two-track career that he has been pursuing until now, with academic work performed at the university, and commercial work, aimed at making crystallographic software accessible to both academia and industry, done in the company. In 2007, Wladek received the Inventor of the Year Award from the University of Virginia Patent Foundation, and throughout the years HKL Research made substantial contributions to the University budget through royalties.

It is hard to overestimate the importance of Wladek's contributions to structural biology, and especially to methods development in this important area of science. His paper, entitled "Processing of X-ray diffraction data collected in oscillation mode" (Otwinowski et al., 1997), written together with Zbyszek Otwinowski, became one of the most highly cited structural biology papers in history, having garnered more than 37,000 citations as of the end of 2020. For many years, the methods and software for data processing that were described in that seminal publication have been used to determine the crystal structures of the majority of proteins and other macromolecules throughout the world. Wladek has continued his work with the development of methods that would lead not only to efficient processing of diffraction data, but also to the possibility of solving crystal structures with just a few clicks of the computer mouse. $\mathrm{He}$ developed an integrated package named HKL-3000 that he described in another seminal publication (Minor et al., 2006). HKL-3000 integrates many computer programs available as part of CCP4 (Winn et al., 2011), as well as several utilities developed by his lab (Porebski et al., 2016) and by other leaders in crystallographic software (Kowiel et al., 2014). The continuously optimized settings for the programs integrated within HKL-3000 allow seamless structure solution and refinement by both experts and novices in the field. Wladek is very often sought as an expert consultant for improvement of various data collection facilities at a number of synchrotron centers worldwide.

The development of very efficient methods of structure determination was crucial for the multi-year effort named "structural genomics", aimed at determining protein structures on a truly industrial scale. Wladek became critically involved with several structural genomics centers (CSGID, MSCG, NYSGRC, Enzyme Function Initiative), where he was responsible for data management, structure solution tools, as well as quality control of the crystal structures. These centers were all working in that area and they made very strong impact on our understanding of the relationship between the structure and function of biological macromolecules. The structural genomics projects have been also very important in providing knowledge that has led to the development of new and better drugs. The databases and web servers (e.g. https://csgid.org/pages/home) developed by Wladek were (and still are) absolutely crucial for the success of these projects because they allowed for efficient handling of thousands of protein targets and millions of experiments. A summary of the accomplishments of the structural genomics initiatives was published by Wladek in 2016 (Grabowski et al., 2016a). At the same time, he noticed that while the structural genomics initiatives were very efficient in generating new experimental data, there was a significant lag in the analysis of the results, as well as their delivery to the scientific community (Chruszcz et al., 2010). Therefore, he became involved in work on the development of webpage tools that would efficiently distribute the results of the structural genomics groups (Berman et al., 2009; Gabanyi et al., 2011; Gerlt et al., 2011; Berman et al., 2015).

Wladek's other major contribution to the field of structural biology is in the area of validation and improvement of published crystal structures. Well over 175,000 structures are currently present in the Protein Data Bank (PDB) (Berman et al., 2000) and while the majority of them are without any major flaws, by the sheer number it is inevitable that the quality of some of them is not always fully acceptable. Together with an international group of scientists known in popular parlance as "The Polish Crystallographic Mafia" he has been deeply involved in verifying and correcting many crystal structures (Wlodawer et al., 2018), including structures of such important drug targets as metallo- $\beta$-lactamases (Raczynska et al., 2018), proteins binding the anticancer drug cis-platin (Shabalin et al., 2015), or proteins encoded by or interacting with the new SARS-CoV-2 coronavirus, the agent responsible for the pandemic of COVID-19 (Wlodawer et al., 2020; Brzezinski et al., 2020). Wladek is a coauthor of approximately 450 structures in the PDB.

Wladek's special attention is always directed towards proper modeling of metals and metal binding sites. The story of his work on metal validation started with a comment of a reviewer of one of his manuscripts. The reviewer noticed that a calcium binding site in the described structure was not modeled in an optimal way, and the distances between the metal and the coordinating oxygen atoms were slightly too long. This prompted Wladek not only to correct that structure, but also initiated a completely new project that resulted in the creation of the CheckMyMetal Validation Server (Zheng et al., 2008; Zheng et al., 2014; Zheng et al., 2017). Initially Wladek was concentrating on metals in protein molecules, but later he also expanded his interest to RNA structures (Zheng et al., 2015). The story of the development of the tools for analysis and validation of metal binding sites illustrates well one of the most important aspects of Wladek's aptitude to deal with something that initially looks like a problem, for example a critical review of a manuscript. Specifically, Wladek always chooses to excel himself and his research group in order to overcome problems or difficulties and treats them as opportunities to improve his scientific skills, as well as using them as a guidepost to explore new research directions. On the same note, his scientific curiosity and genuine enthusiasm when working on research projects allow him to easily attract people who are interested in the solution of a particular scientific problem.

Wladek's laboratory at the University of Virginia has become a hub for training a new generation of structural biologists. At least ten former members of his laboratory now hold professorship or equivalent appointments in a number of scientific institutions in Poland, United States, and other countries (https://minorlab.org/people/ alumni/). Others work in top world companies such as Google, which employs three of Wladek's former trainees. To date, Wladek's laboratory lists 113 alumni, many 


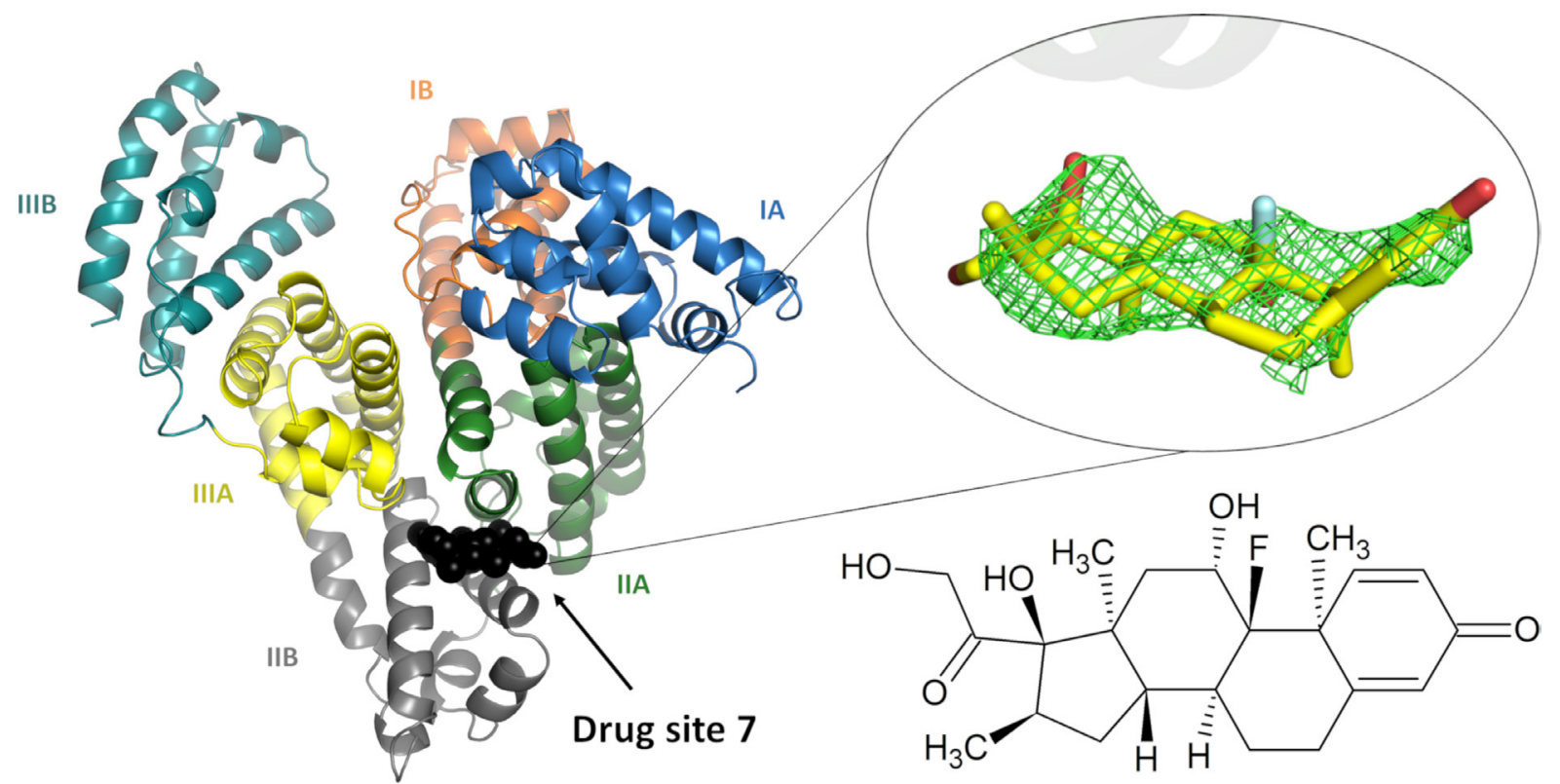

Figure 2. The overall structure of the equine serum albumin-dexamethasone complex.

The $\mathrm{mFo}$ - DFc electron density for dexamethasone is shown as a green mesh. Albumin subdomains are shown in different colors and labeled with Roman numerals and letters. The dexamethasone molecule is shown in stick representation with $\mathrm{C}$ atoms in yellow, $\mathrm{O}$ atoms in red, and the $\mathrm{F}$ atom in cyan. The chemical structure of dexamethasone is displayed in the same orientation as the stick model. Reproduced with permission of the International Union of Crystallography from a paper by Shabalin and coworkers (Shabalin et al., 2020).

of whom recall having a very creative and collaborative time in his laboratory. At its peak in 2010-2013, the laboratory had about 25 members, which enabled a unique multidisciplinary environment of structural biologists, software developers, and data scientists. Wladek also coauthored a number of teaching texts that are widely used by students in the field of macromolecular crystallography (Wlodawer et al., 2013) and created a public database for the deposition of primary crystallographic data (Grabowski et al., 2016b). One of his mottos is "transparency, quality and reproducibility".

For many years Wladek's laboratory has been a meeting place of students and postdocs from Poland who worked at the University of Virginia. In fact, thanks to Wladek and Professor Zygmunt Derewenda, a significant fraction of students in the University of Virginia's Interdisciplinary Biophysics Program came from Poland. However, visitors to Wladek's lab are not only associated with the science departments located at Pinn Hall (formerly Jordan Hall) of the University of Virginia School of Medicine. Wladek has a custom of walking with a cup of coffee through buildings and links of the School of Medicine complex and discussing with lab members interesting ongoing projects. As the discussions are often in Polish, they attract attention of various passersby, and very often result in their invitation to the laboratory or to Wladek's home. The legendary meetings organized at Wladek's home also provide numerous opportunities for students and other lab members to meet in a less formal setting with top scientists working not only in the field of structural biology.

Wladek and Iwona's home is not only a meeting place for both, scientific and Polish communities, but quite often (before the time of Airbnb) is a temporary hostel for people who had just arrived in Charlottesville to begin their work at the University of Virginia. Therefore, it is also not unusual for Professor Minor to serve as a "taxi service" and to help newcomers in finding a place to live, as well as to familiarize them with the city. In several cases, Wladek also helped the spouses of arriving scientists to find a job, for example at HKL Research. Therefore, it is not surprising that many of Wladek's former mentees continue to work with him long after they have finished their official training in his laboratory. In fact, some of the new young scientists working in Wladek's group are students of his former mentees.

There is something special about Wladek's personality and his research attitude, as he is able to attract people with different scientific backgrounds, such as biology, bioinformatics, chemistry, computer science, medicine, physics, etc. It allows the group members to approach the projects on which they are working from completely unexpected perspectives, as well as learning from each other. Wladek's approach is to involve people in many collaborative interactions; this strategy has resulted in an impressive productivity of his group. Similarly, he encourages his postdoctoral research associates to explore new research topics, which they could later use to start their independent careers.

Wladek's scientific career is an odyssey of agility: he worked in and switched between multiple scientific disciplines. He started in physics and then moved to protein crystallography, which is still his main field. While being primarily focused on protein crystallography, he also successfully ventured into software development, databases, bioinformatics, data science, and various biomedical projects, most recently the fight against COVID-19 (Wlodawer et al., 2020; Brzezinski et al., 2020), including structural investigations of the transport by albumin of a COVID-19 drug, dexamethasone (Shabalin et al., 2020) (Fig. 2).

Whereas many scientists reaching the age of 75 are retired and no longer active, Wladek is not yet ready to be put out to pasture. Although he is occasionally talking about retiring and focusing on his other passion - skiing (Fig. 3) - we seriously doubt that he will slow down his research any time soon. Here, we would like to note that even skiing is not completely distracting Wladek 


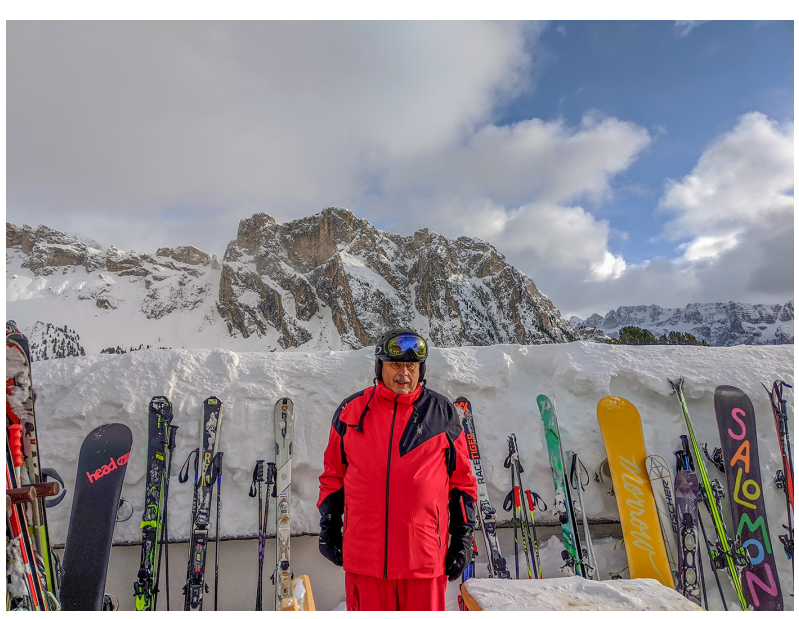

Figure 3. Wladek Minor engaged in his other important pursuit - skiing in the Italian Alps, winter 2019.

from science, as he has a custom of calling his laboratory from a ski lift to check on the progress of projects. He published a dozen important papers in 2019 and another dozen in 2020. His career and achievements are a true inspiration to others and the source of pride for "Polish science".

\section{REFERENCES}

Berman HM, Gabanyi MJ, Groom CR, Johnson JE, Murshudov GN, Nicholls RA, Reddy V, Schwede T, Zimmerman MD, Westbrook J, Minor W (2015) Data to knowledge: how to get meaning from your result. IUCrJ 2: 45-58. https://doi.org/10.1107/s2052252514023306

Berman HM, Westbrook J, Feng Z, Gilliland G, Bhat TN, Weissig H, Shindyalov IN, Bourne PE (2000) The Protein Data Bank. Nucleic Acids Res 28: 235-242. https://doi.org/10.1093/nar/28.1.235

Berman HM, Westbrook JD, Gabanyi MJ, Tao W, Shah R, Kouranov A, Schwede T, Arnold K, Kiefer F, Bordoli L, Kopp J, Podvinec M, Adams PD, Carter LG, Minor W, Nair R, La Baer J (2009) The protein structure initiative structural genomics knowledgebase. $\mathrm{Nu}$ cleic Acids Res 37: D365-D368. https://doi.org/10.1093/nar/gkn790

Brzezinski D, Kowiel M, Cooper DR, Cymborowski M, Grabowski M, Wlodawer A, Dauter Z, Shabalin IG, Gilski M, Rupp B, Jaskolski M, Minor W (2021) Covid-19.bioreproducibility.org: A web resource for SARS-CoV-2-related structural models. Protein Sci 30: 115-124. https://doi.org/10.1002/pro.3959

Chruszcz M, Domagalski M, Osinski T, Wlodawer A, Minor W (2010) Unmet challenges of structural genomics. Curr Opin Struct Biol 20: 587-597. https://doi.org/10.1016/j.sbi.2010.08.001

Gabanyi MJ, Adams PD, Arnold K, Bordoli L, Carter LG, FlippenAndersen J, Gifford L, Haas J, Kouranov A, McLaughlin WA, Micallef DI, Minor W, Shah R, Schwede T, Tao YP, Westbrook JD, Zimmerman M, Berman HM (2011) The Structural Biology Knowledgebase: a portal to protein structures sequences functions and methods. J Struct Funct Genomics 12: 45-54. https://doi.org/10.1007/ s10969-011-9106-2

Gerlt JA, Allen KN, Almo SC, Armstrong RN, Babbitt PC, Cronan JE, Dunaway-Mariano D, Imker HJ, Jacobson MP, Minor W, Poulter CD, Raushel FM, Sali A, Shoichet BK, Sweedler JV (2011) The enzyme function initiative. Biochemistry 50: 9950-9962. https:// doi.org/10.1021/bi201312u
Grabowski M, Langner KM, Cymborowski M, Porebski PJ, Sroka P, Zheng H, Cooper DR, Zimmerman MD, Elsliger MA, Burley SK, Minor W (2016a) A public database of macromolecular diffraction experiments. Acta Crystallogr D72: 1181-1193. https://doi. org/10.1107/S2059798316014716

Grabowski M, Niedzialkowska E, Zimmerman MD, Minor W (2016b) The impact of structural genomics: the first quindecennial. I Struct Funct Genomics 17: 1-16. https://doi.org/10.1007/s10969-016-9201-5

Kowiel M, Jaskolski M, Dauter Z (2014) ACHESYM: an algorithm and server for standardized placement of macromolecular models in the unit cell. Acta Crystallogr D70: 3290-3298. https://doi.org/10.1107/ S1399004714024572

Minor W, Cymborowski M, Otwinowski Z, Chruszcz M (2006) HKL3000: The integration of data reduction and structure solution from diffraction images to an initial model in minutes. Acta Crystallogr D62: 859-866. https://doi.org/10.1107/S0907444906019949

Otwinowski Z, Minor W (1997) Processing of X-ray diffraction data collected in oscillation mode. Methods Enzymol 276: 307-326. https://doi.org/10.1016/S0076-6879(97)76066-X

Porebski P. J, Cymborowski M, Pasenkiewicz-Gierula M, Minor W (2016) Fitmunk: improving protein structures by accurate automatic modeling of side-chain conformations. Acta Crystallogr D72: 266280. https://doi.org/10.1107/S2059798315024730

Raczynska JE, Shabalin IG, Minor W, Wlodawer A, Jaskolski M (2018) A close look onto structural models and primary ligands of metallo-beta-lactamases. Drug Resist Updat 40: 1-12. https://doi. org/10.1016/j.drup.2018.08.001

Shabalin I, Dauter Z, Jaskolski M, Minor W, Wlodawer A (2015) Crystallography and chemistry should always go together: a cautionary tale of protein complexes with cisplatin and carboplatin. Acta Crystallogr D71: 1965-1976. https://doi.org/10.1107/S139900471500629X

Shabalin IG, Czub MP, Majorek KA, Brzezinski D, Grabowski M, Cooper DR, Panasiuk M, Chruszcz M, Minor W (2020) Molecular determinants of vascular transport of dexamethasone in COVID-19 therapy. IUCrJ 7: 1048-1058. https://doi.org/10.1107/ S2052252520012944

Winn MD, Ballard CC, Cowtan KD, Dodson EJ, Emsley P, Evans PR, Keegan RM, Krissinel EB, Leslie AG, McCoy A, McNicholas SJ, Murshudov GN, Pannu NS, Potterton EA, Powell HR, Read RJ, Vagin A, Wilson KS (2011) Overview of the CCP4 suite and current developments. Acta Crystallogr D67: 235-242. https://doi. org/10.1107/S0907444910045749

Wlodawer A, Dauter Z, Porebski PJ, Minor W, Stanfield R, Jaskolski M, Pozharski E, Weichenberger CX, Rupp B (2018) Detect correct retract: How to manage incorrect structural models. FEBS J 285: 444-466. https://doi.org/10.1111/febs.14320

Wlodawer A, Dauter Z, Shabalin IG, Gilski M, Brzezinski D, Kowiel M, Minor W, Rupp B, Jaskolski M (2020) Ligand-centered assessment of SARS-CoV-2 drug target models in the Protein Data Bank. FEBS J 287: 3703-3718. https://doi.org/10.1111/febs.15366

Wlodawer A, Minor W, Dauter Z, Jaskolski M (2013) Protein crystallography for aspiring crystallographers or how to avoid pitfalls and traps in macromolecular structure determination. FEBS J 280: 5705-5736. https://doi.org/10.1111/febs.12495

Zheng H, Chordia MD, Cooper DR, Chruszcz M, Muller P, Sheldrick GM, Minor W (2014) Validation of metal-binding sites in macromolecular structures with the CheckMyMetal web server. Nat Protoc 9: 156-170. https://doi.org/10.1038/nprot.2013.172

Zheng H, Chruszcz M, Lasota P, Lebioda L, Minor W (2008) Data mining of metal ion environments present in protein structures. J Inorg Biochem 102: 1765-1776. https://doi.org/10.1016/j.jinorgbio.2008.05.006

Zheng H, Cooper DR, Porebski PJ, Shabalin IG, Handling KB, Minor W (2017) CheckMyMetal: a macromolecular metal-binding validation tool. Acta Crystallogr D73: 223-233. https://doi.org/10.1107/ S2059798317001061

Zheng H, Shabalin IG, Handing KB, Bujnicki JM, Minor W (2015) Magnesium-binding architectures in RNA crystal structures: validation, binding preferences, classification and motif detection. Nucleic Acids Res 43: 3789-3801. https://doi.org/10.1093/nar/gkv225 